\title{
Fabrication of the pyramidal microstructure on silicon substrate using $\mathrm{KOH}$ solution
}

\author{
Yaqin Wang, Ruizhi Luo, Junjun Ma and Shi-Qing Man * \\ School of Physics and Electronic Information, Yunnan Normal University, Kunming, Yunnan, \\ China \\ yaqin_w@yeah.net, 1401820876@qq.com, 896695508@qq.com, \\ man_shiqing@yahoo.com
}

\begin{abstract}
Keywords: pyramid, $\mathrm{KOH}$, microstructure, fabrication.
Abstract. The texturization of monocrystalline silicon wafers using a mixture of potassium hydroxide and isopropyl alcohol solutions has been investigated. The texture morphology and pyramid size are affected by the $\mathrm{KOH}$ concentration, the temperature and the time together. The surface reflectance and the surface morphology were measured with a UV-Visible Spectrophotometer and a scanning electronic microscope (SEM) respectively. We reported a relatively uniform size, dense arrangement pyramid microstructure on the basement of silicon texture. According to the reflectance and SEM patterns, we got the appropriate concentration of $\mathrm{KOH}, 20 \mathrm{wt} \%$ and $25 \mathrm{wt} \%$, with the corresponding reflectance were $12.049 \%$ and $14.593 \%$. It means that either too low temperature with a long time or too high temperature with a short can damage the formation. We got the surface morphology, which was consisted of 1-1.5 $\mu \mathrm{m}$ sized pyramids. From the pyramid dimension, the optimum process condition was found to be $20 \mathrm{wt} \% \mathrm{KOH}, 3 \mathrm{wt} \% \mathrm{IPA}, 60^{\circ} \mathrm{C}$ and $5 \mathrm{~min}$ at which was reduced to $1.292 \mu \mathrm{m}$. From the SEM images density and uniformity, the optimized condition is $20 \mathrm{wt} \% \mathrm{KOH}$, $3 \mathrm{wt} \% \mathrm{IPA}, 70^{\circ} \mathrm{C}$ and $15 \mathrm{mins}$ though its size has reached the $1.404 \mu \mathrm{m}$.
\end{abstract}

\section{Introduction}

The microstructure of monocrystalline silicon influences their physical properties and determines the stability and effective of the optical absorption [1-3]. In traditional technological application, the silicic microstructure has been applied on the solar cell to reducing optical losses [4,5]. A lot of metallic substrates display unique surface plasmon properties that have attached enough scientific interest and great technological importance[2,4]. Metallic microstructure has been widely used on the micromachining such as nanophotonic devices, data storage, and biosensor[3,4]. Recently, the silicon nanofabrication of crystalline silicon has been widely used with silicon nanoscale waveguide devices and quantum effect devices. If the silicon microstructure has reached nanometer, it also should can be used on technological field[3,4,6-8]. To control the shape of pyramid microstructure in wet etching, it is necessary to meticulously design the etching conditions such as, the solution concentration, the temperature and the time[6-7,9].

In the process of monocrystalline microstructure fabrication, alkaline solution is customarily used to make pyramid structure with its anisotropic etching characteristic of $<100>$ silicon. The theory is caused by the difference on the (100) and (111) directions since the etching rate on the (111) direction is much slower than (100) direction [5, 10-11]. Adding isopropyl alcohol (IPA) can improve the wettability of silicon surface and control the etching rate by preventing an explosive reaction between the silicon surface and the $\mathrm{OH}-$ ions [12-13]. Aqueous $\mathrm{KOH}$ solution etched $\mathrm{Si}$ is mainly via chemical equation below [10,11].

$$
\mathrm{Si}+4 \mathrm{OH}^{-} \rightarrow \mathrm{Si}(\mathrm{OH})_{4}+4 \mathrm{e}^{-}
$$

In this paper, texture of monocrystalline silicon wafers with a potassium hydroxide solution was studied. Meanwhile, the changes of size for pyramidal microstructure on silicon substrate with etching time, the concentration of $\mathrm{KOH}$ and temperature were also investigated. 


\section{Experimental}

\section{Microstructure preparation .}

In this work, attempts have been made for comparative study of etching the monocrystalline silicon wafer surface by $\mathrm{KOH}$. The monocrystalline silicon is 100 oriented, p-doped and the resistivity is about $0.5 \Omega \sim 2 \Omega$. The size is about $15 \mathrm{~mm} \times 15 \mathrm{~mm}$ that cut from the $125 \mathrm{~mm} \times 125 \mathrm{~mm}$ square.

Before etching, wafers were cleaned by the following procedures. The silicon etching process was mainly involved in the hydroxyl ion (OH-) which attacks the silicon surface by controlling affecting factors. Before etching, the samples were immersed in ethyl alcohol at ultrasonic clearing machine for 5 mins to remove impurity. Then, have treated wafer be rinsing with the flowing deionized water. After rinsing, the samples were dried on the drying cabinet in preparation for following steps. The cleaned wafer was took place in the alkaline mixture solution.

\section{Microstructure fabrication .}

The whole reaction process was conducted in heating magnetic stirring apparatus. First, the experiment was conducted that the $\mathrm{KOH}$ concentration was varied from $15 \mathrm{wt} \%$ to $30 \mathrm{wt} \%$, for the $5 \mathrm{wt} \%$ IPA addition interval. The purpose of this experiment is to get the minimum reflectivity and roughly find out the better morphology. Next, through the study of above, this work mainly concentrate on the $20 \mathrm{wt} \%$ and $25 \mathrm{wt} \% \mathrm{KOH}$ with $3 \mathrm{wt} \%$ IPA additive. The different reaction times and reaction temperatures could be adjusted. In this experiment, we considered the etching temperature $\left(60^{\circ} \mathrm{C}\right.$ and $\left.70^{\circ} \mathrm{C}\right)$, the etching time $(5 \mathrm{~min}$ and $15 \mathrm{~min}$ and investigated its effect on the texturization of the silicon wafer. We examined the effect by the change of temperature and time respectively. After the etching process, the samples were rinsed and dried again. Arrays of microstructure elements of size $1 \mu \mathrm{m} \times 1 \mu \mathrm{m}$ were patterned in a $\mathrm{SiO} 2$ layer by etching rate of the (100) silicon plane. The total hemispherical reflectance was measured by Shimadzu UV-2600 spectrophotometer (Shimadzu Inc., Japan) equipped with an integrating sphere. The surface morphology was studied with Zeiss EVO MA10 (Carl-Zeiss, Germany) scanning electron microscope (SEM).Table 1 shows the experiment groups and procedure.

Table 1 Experiment groups and procedures

\begin{tabular}{lll}
\hline Step & Procedure & Reagents and instruments \\
\hline 1 & Rinse & XYE-10-H deionizer \\
2 & Remove saw damage & hydrogen peroxide, ethyl alcohol \\
3 & Texturing & KOH, IPA \\
4 & Rinse against after reaction & ultrapure water, ethyl alcohol \\
5 & Drying & drying machine \\
6 & Measurement & UV-2006, The EVO MA15 type of \\
& & scanning electron microscope
\end{tabular}

\section{Results and discussion}

At first, we investigated the dependence of the surface reflectance on $\mathrm{KOH}$ concentration. Etching was carried out at $80 \mathrm{oC}, 30 \mathrm{~min}$, and $5 \mathrm{w} \%$ IPA. The reflectance with different concentrations of $\mathrm{KOH}(15 \mathrm{wt} \%, 20 \mathrm{wt} \%, 25 \mathrm{wt} \%$ and $30 \mathrm{w} \%)$ was investigated. The reflectance variation is shown in Fig. 1 line chart.

Table 2 shows the corresponding average reflectance of each concentration solution. The average reflectance was weighted in the spectrum range of $400-800 \mathrm{~nm}$. The weighted reflectance (WR) was calculated normalizing the pyramidal by UV-2600. Fig.2 (a-d) presents the SEM images of silicon substrate morphology that we can make a qualitative analysis [10-11]. The low reflectance could be 
explained by the formation of uniformly and shaped pyramids on the surface of silicon etched using the appropriate concentration of $\mathrm{KOH}$ as observed in Fig. 2 (b) and (c). When the $\mathrm{KOH}$ concentration was increased to $30 \mathrm{wt} \%$, the pyramidal structure began to collapse.

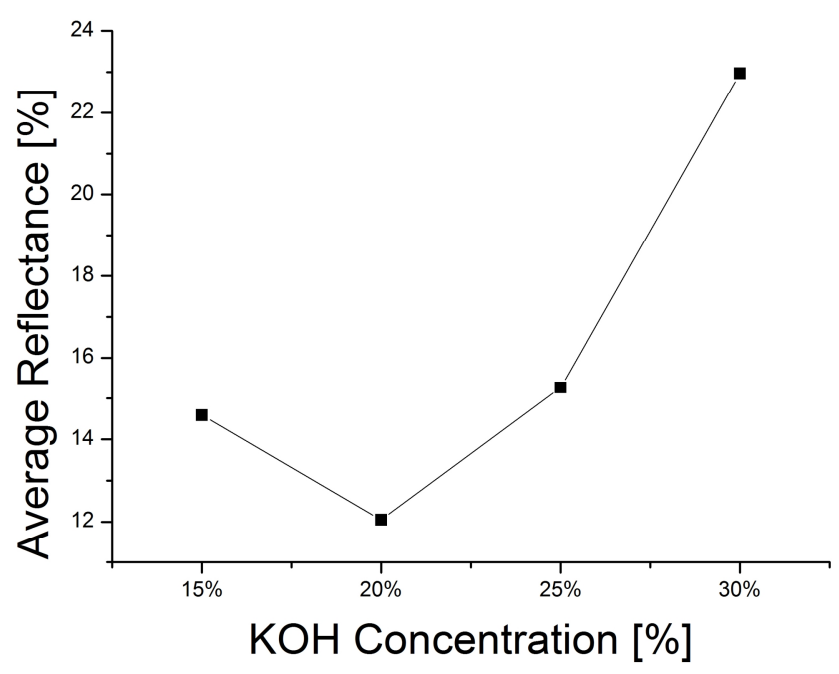

Fig.1. Pyramidal reflectance of $\mathrm{KOH}$ textured sample using 5wt\% IPA surface active agent.

Table 2 Experimental condition of $\mathrm{KOH}$ texture in preliminary experiment

\begin{tabular}{l|l|l|l|l}
\hline The concentration & $15 \mathrm{wt} \%$ & $20 \mathrm{wt} \%$ & $25 \mathrm{wt} \%$ & $30 \mathrm{wt} \%$ \\
\hline The reflectance (\%) & 15.266 & 12.049 & 14.593 & 22.967 \\
\hline
\end{tabular}
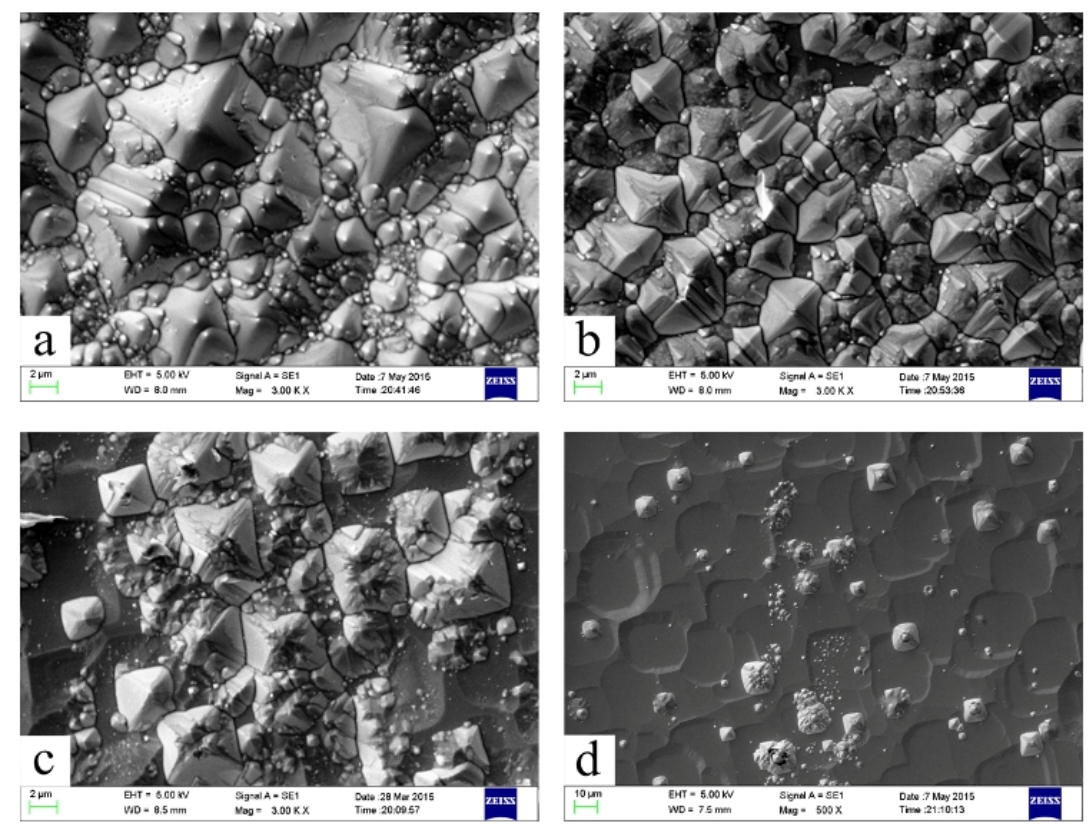

Fig.2. SEM images of silicon surface after etching with $\mathrm{KOH}+5 \mathrm{wt} \%$ IPA mixture solution: (a) $15 \mathrm{wt} \% \mathrm{KOH}$, (b) $20 \mathrm{wt} \% \mathrm{KOH}$, (c) $25 \mathrm{wt} \% \mathrm{KOH}$, and (d) $30 \mathrm{wt} \% \mathrm{KOH}$ heating in $80^{\circ} \mathrm{C}$ water bath for 5 mins.

And then, we investigated the surface reflectance about time and temperature separately. According to previous studies, the concentration of $\mathrm{KOH}$ was fixed at $20 \mathrm{wt} \%$ and $25 \mathrm{wt} \%$ respectively. Table 3 records the etching parameters respectively from Sample (a) - (d1).

By referring to the literature [13], we evaluated the homogeneity by calculating the pyramids average size. As the scale bar indicates $2 \mu \mathrm{m}$, the length of line is $40 \mu \mathrm{m}$. Then count the number of pyramids caught by the diagonal lines. Table 4 displayed the length of diagonal by number of pyramid gave the average value of pyramids size. 
When subsequently texturing is processed, random pyramids are formed on the silicon substrate.

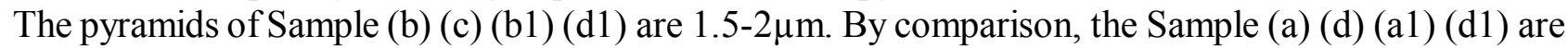
just $1-1.5 \mu \mathrm{m}$ which was excellent.

Figure. 3 (a-b) shows the results of texturing using $20 \mathrm{wt} \% \mathrm{KOH}$ with time variation under $60^{\circ} \mathrm{C} . \mathrm{As}$ the etching time is increased, the number of pyramids per unit area decreases and the pyramids become larger. The same situation exists on the $25 \mathrm{wt} \% \mathrm{KOH}$. However, when temperature is $70^{\circ} \mathrm{C}$, the change about the number of pyramids per unit area and the pyramids size is opposite. The rules about change the pyramid values has elaborated that the proportion of temperature and time used on the texturization must be suitable. Either too low temperature with a long time or too high temperature with a short can damage the formation of more uniformly sized and shaped pyramids. So, the evaluation fabrication of nanostructure pyramid is a manifestation of small dimension, dense, uniformly distributed structures formed on the surface of the silicon wafers upon texturization.

The minimum size of average of etched wafer was found to be $1.292 \mu \mathrm{m}$. The SEM image of wafer textured at the optimum is shown in Fig.3 (a). The densest and the most uniform structure were shown in Fig. (d) though its size is $1.404 \mu \mathrm{m}$.

Table 3 Etching solution proportioning and reaction conditions

\begin{tabular}{lllll}
\hline Group & Etching solution & Surfactant & Temperature & Time \\
\hline $1 \#$ & $20 \mathrm{w} \% \mathrm{KOH}$ & $3 \mathrm{w} \%$ IPA & $60^{\circ} \mathrm{C}$ & $5 \mathrm{mins}$ \\
$2 \#$ & $20 \mathrm{w} \% \mathrm{KOH}$ & $3 \mathrm{w} \% \mathrm{IPA}$ & $60^{\circ} \mathrm{C}$ & $15 \mathrm{~min}$ \\
$3 \#$ & $20 \mathrm{w} \% \mathrm{KOH}$ & $3 \mathrm{w} \% \mathrm{IPA}$ & $70^{\circ} \mathrm{C}$ & $5 \mathrm{mins}$ \\
$4 \#$ & $20 \mathrm{w} \% \mathrm{KOH}$ & $3 \mathrm{w} \% \mathrm{IPA}$ & $70^{\circ} \mathrm{C}$ & $15 \mathrm{mins}$ \\
$5 \#$ & $25 \mathrm{w} \% \mathrm{KOH}$ & $3 \mathrm{w} \% \mathrm{IPA}$ & $60^{\circ} \mathrm{C}$ & $5 \mathrm{mins}$ \\
$6 \#$ & $25 \mathrm{w} \% \mathrm{KOH}$ & $3 \mathrm{w} \% \mathrm{IPA}$ & $60^{\circ} \mathrm{C}$ & $15 \mathrm{mins}$ \\
$7 \#$ & $25 \mathrm{w} \% \mathrm{KOH}$ & $3 \mathrm{w} \% \mathrm{IPA}$ & $70^{\circ} \mathrm{C}$ & $5 \mathrm{mins}$ \\
$8 \#$ & $25 \mathrm{w} \% \mathrm{KOH}$ & $3 \mathrm{w} \% \mathrm{IPA}$ & $70^{\circ} \mathrm{C}$ & $15 \mathrm{mins}$ \\
\hline
\end{tabular}
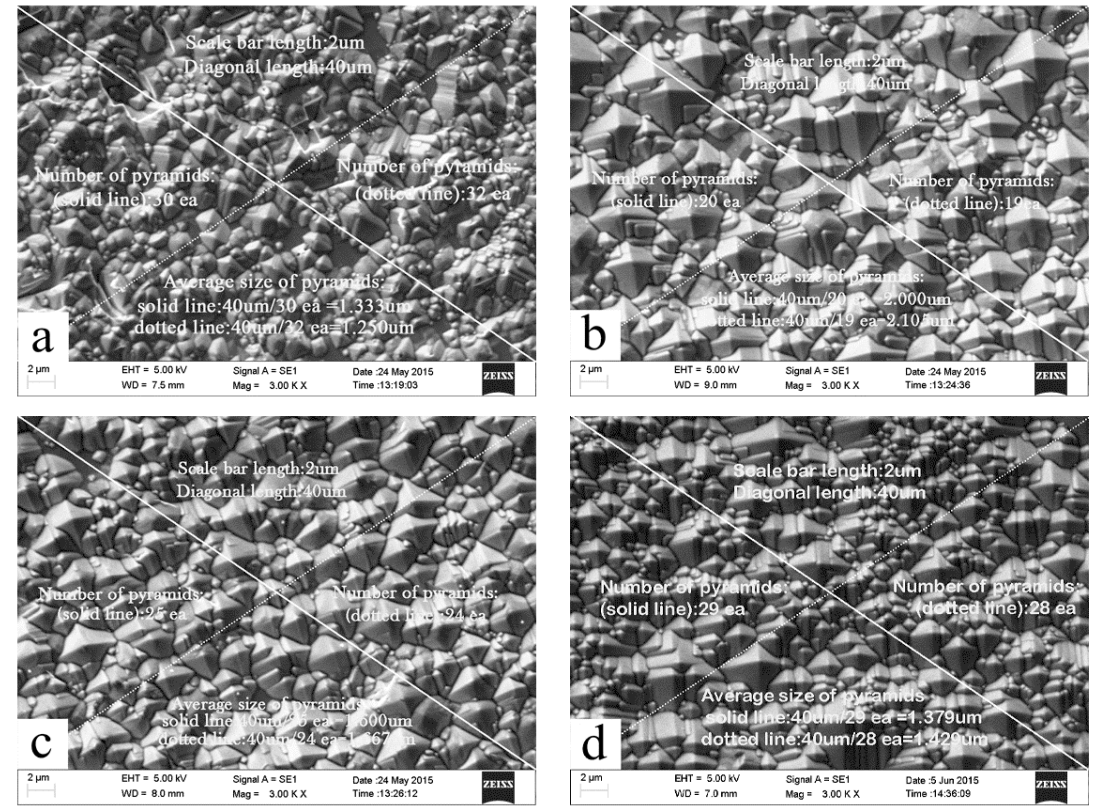

Fig.3. shows the pyramid microstructure on the Si surface on the $20 \mathrm{wt} \% \mathrm{KOH}$. Sample (a) and Sample (b) are in different time under $60^{\circ} \mathrm{C}$. Sample (c) and Sample (d) are in different time under $70^{\circ} \mathrm{C}$. All the SEMS finally were displayed by this form which attached some explanatory word. 
Table 4 The average size of pyramids on the two diagonals

\begin{tabular}{lllllllll}
\hline Group $(\mu \mathrm{m})$ & $1 \#$ & $2 \#$ & $3 \#$ & $4 \#$ & $5 \#$ & $6 \#$ & $7 \#$ & $8 \#$ \\
\hline Solid line & 1.333 & 2.000 & 1.600 & 1.379 & 1.429 & 1.905 & 1.739 & 1.379 \\
Dotted line & 1.250 & 2.105 & 1.667 & 1.429 & 1.333 & 2.000 & 1.818 & 1.333 \\
Average size & 1.292 & 2.053 & 1.634 & 1.404 & 1.381 & 1.953 & 1.779 & 1.356 \\
\hline
\end{tabular}
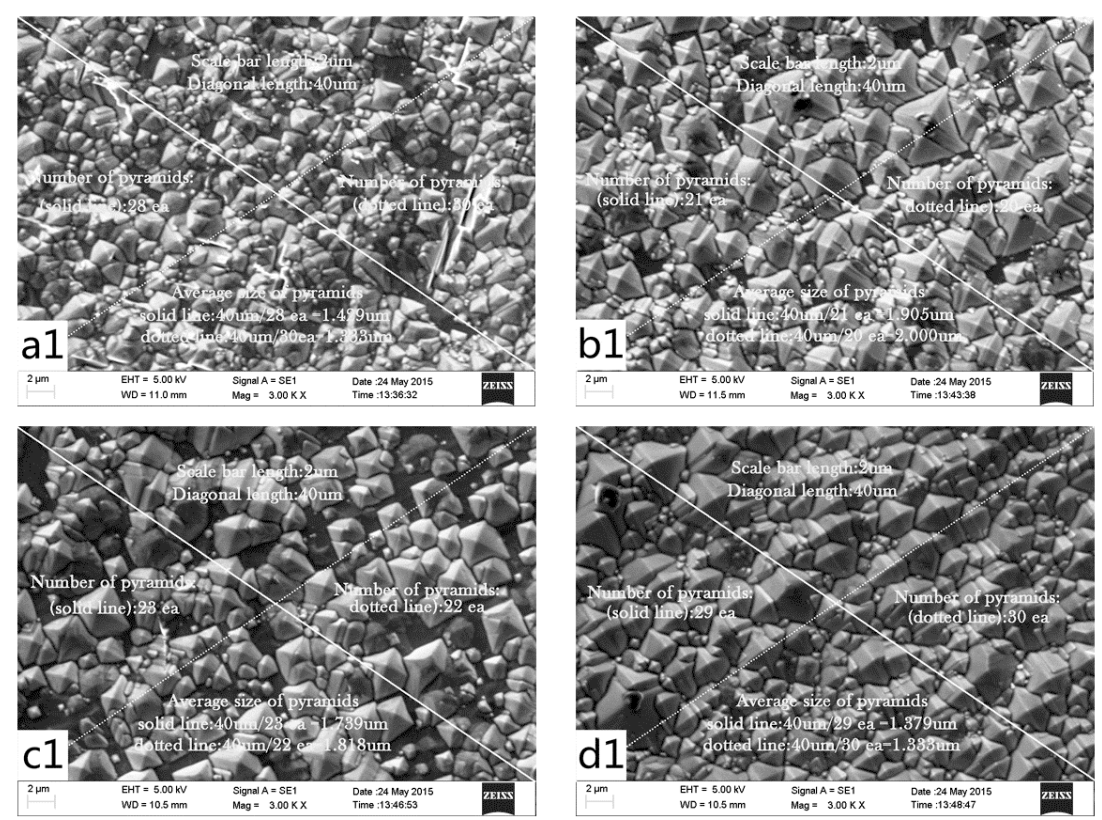

Fig.4. shows the pyramid microstructure on the Si surface on the $25 \mathrm{wt} \% \mathrm{KOH}$. Sample (a1) and Sample (b1) are in different time under $60^{\circ} \mathrm{C}$. Sample (c1) and Sample (d1) are in different time under $70^{\circ} \mathrm{C}$.

\section{Conclusions}

In this paper, we study the texture of monocrystalline silicon wafers with a potassium hydroxide solution. We investigated the changes of pyramid size with the etching time, the concentration of $\mathrm{KOH}$ and temperature. First, in this study, we considered the $\mathrm{KOH}$ in concentrations $(15 \mathrm{wt} \%, 20 \mathrm{wt} \%$, $25 \mathrm{wt} \%$ and $30 \mathrm{wt} \%$ ) with the addition of $5 \%$ IPA and investigated the reflectance. According to previous studies, the concentration of $\mathrm{KOH}$ was fixed at $20 \mathrm{wt} \%$ and $25 \mathrm{wt} \%$ because their reflectance is relatively low, $12.049 \%$ and $14.593 \%$. Our optimized (to obtain the smallest size) for etching process was determined to be: $20 \mathrm{wt} \% \mathrm{KOH}, 3 \mathrm{wt} \%$ IPA, solution temperature $=60^{\circ} \mathrm{C}$ and etching time $=5 \mathrm{~min}$ where the average size of the silicon wafer was $1.292 \mu \mathrm{m}$. Meanwhile, to obtain the dense and uniformly distributed pyramid structures from the SEM images, the optimized condition is $20 \mathrm{wt} \%$ $\mathrm{KOH}, 3 \mathrm{wt} \% \mathrm{IPA}, 70^{\circ} \mathrm{C}$ and $15 \mathrm{mins}$.

\section{Acknowledgment}

This work was supported by the National Natural Science Foundation of China (NSFC) (Grant No. 21171072 and Grant No. 21361028).

\section{References}

[1] McKenzie,02D.02R, Cockayne,02D.02J.02H, Sceats,02M.02G, et al. Microstructure of zi rcon is films deposited with ion assistance[J]. Journal of Materials Science, 1987, 22(10):3725-3731.

[2] Sun C H, Linn N C, Jiang P. Templated Fabrication of Periodic Metallic Nanopyramid Arrays[J]. Chemistry of Materials, 2007.

[3] Fang, Du, Lebedkin, et al. Gold mesostructures with tailored surface topography and their self-assembly arrays for surface-enhanced Raman spectroscopy.[J]. Nano Letters, 2010, 10(12):5006-5013. 
[4] Koschwitz T, Meinel B, Acker J. Application of Confocal Microscopy to Evaluate the Morphology of Acidic Etched Mc-silicon [J]. Energy Procedia, 2013:234-242.

[5] Hayoung Park, Joon Sung Lee, Hee Jin Lim and Donghwan Kim. The Effect of Tertiary-Butyl Alcohol on the Texturing of Crystalline Silicon Solar Cells[J]. Journal of the Korean Physical Society, Vol. 55, No. 5, November 2009, pp. 1767-1771

[6] Han W, Yang X, Wang Y, et al. Fabrication method of silicon nanostructures by anisotropic etching[C]//Group IV Photonics, 2008 5th IEEE International Conference on. IEEE, 2008:146 148.

[7] Lin, Ying-Yi, Liao, Jiunn-Der, Ju, Yu-Hung, et al. Focused ion beam-fabricated Au micro/nanostructures used as a surface enhanced Raman scattering-active substrate for trace detection of molecules and influenza virus.[J]. Nanotechnology, 2011, 22(18):185308-185315(8).

[8] Trompoukis C, Abdo I, Cariou R, et al. Photonic nanostructures for advanced light trapping in thin crystalline silicon solar cells [J]. Physica Status Solidi, 2015, 212(1):140-155.

[9] Hugall J T, Baumberg J J, Mahajan S. Surface-enhanced Raman spectroscopy of CdSe quantum dots on nanostructured plasmonic surfaces[J]. Applied Physics Letters, 2009, 95(14):141111 141111-3.

[10]Vernon K C, Davis T J, Scholes F H, et al. Physical mechanisms behind the SERS enhancement of pyramidal pit substrates[J]. Journal of Raman Spectroscopy, 2010, 41(10):1106-1111.

[11]Biswas K, Kal S. Etch characteristics of $\mathrm{KOH}$, TMAH and dual doped TMAH for bulk micromachining of silicon[J]. Microelectronics Journal, 2006, 37(6):519-525.

[12]Jinsu Yoo, Junsik Cho, Kyumin Han, et al. RIE surface texturing for optimum light trapping in multicrystalline silicon solar cells[J]. Journal of the Korean Physical Society, 2012, 60(12):2071-2074.

[13]Park H, Kwon S, Lee J S, et al. Improvement on surface texturing of single crystalline silicon for solar cells by saw-damage etching using an acidic solution [J]. Solar Energy Materials \& Solar Cells, 2009, 93(10):1773-1778. 